\title{
PELATIHAN PEMBUATAN LAPORAN KEUANGAN DANA BOS DENGAN OBJEK KEPALA SEKOLAH, BENDAHARA DAN ADMINISTRASI SMP KOTA TANGERANG SELATAN
}

\author{
${ }^{1}$ R. Chepi Safei Jumhana, ${ }^{2}$ Nopi Oktavianti, ${ }^{3}$ Aprilia Astuti, ${ }^{4}$ Agus Supriatna, \\ ${ }^{5}$ Reza Oktavian \\ Dosen Fakultas Ekonomi Universitas Pamulang \\ Email : ${ }^{2}$ octavianti24@gmail.com
}

\begin{abstract}
ABSTRAK
Kegiatan Pengabdian Kepada Masyarakat ini bertujuan mentransfer pengetahuan dan teknik pembuatan laporan keuangan Dana BOS kepada Kepala, Bendahara dan Administrasi Sekolah Menengah Pertama Kota Tangerang Selatan, agar dapat membantu sekolah dalam menyusun dan mengelola laporan keuangan dana BOS. LPJ atau Laporan Pertanggungjawaban Keuangan BOS merupakan unsur penting dalam program pemerintah, laporan ini akan akan memberikan gambaran bagaimana manajemen pengelolaan keuangan BOS disekolah yang kemudian dilaporkan hingga ke tingkat Menteri.

Hasil kegiatan menunjukan bahwa sebelum pelaksanaan PKM Kepala, Bendahara maupun bagian Administrasi SMP Kota Tangerang Selatan masih kurang menguasai mengenai pengelolaan laporan keuangan dana BOS, namun setelah pelaksanaan kegiatan dilakukan peserta kegiatan PKM ini sudah dapat menguasai terkait pengelolaan laporan keuangan dana BOS, ini semua dapat terlihat dari hasil post test yang diberikan kepada peserta saat kegiatan PKM ini berlangsung.

Metode kegiatan yang digunakan adalah berdiskusi bersama kepada Kepala, Bendahara dan Administrasi SMP Kota Tangerang Selatan terkait permasalahan pembuatan laporan keuangan dalam pengelolaan dana BOS yang akan dilaporkan, sehingga dapat memberikan solusi yang tepat dalam pembuatan laporan keuangan dana BOS tersebut. Setelah itu peserta diberikan pelatihan melalui pembekalan materi dan kemudian peserta diminta mengerjakan soal latihan atau post test terkait pembuatan laporan keuangan dana BOS tersebut.
\end{abstract}

\section{Kata Kunci : PKM, Laporan Keuangan, Dana BOS}

\section{PENDAHULUAN}

Dana Bantuan Operasional sekolah (BOS) adalah program pemerintah yang pada dasarnya adalah untuk penyediaan biaya operasi non personalia bagi satuan pendidikan dasar sebagai pelaksanaan program wajib belajar. Menurut peraturan Mendiknas nomor 69 tahun 2009 standar biaya operasi non personalia adalah standar biaya yang diperlukan untuk membiayai kegiatan operasi nonpersonalia selama 1 tahun sebagai bagian dari keseluruhan dana pendidikan agar satuan 
pendidikan dapat melakukan kegiatan secara teratur dan berkelanjutan sesuai standar nasional pendidikan.

Tujuan Bantuan Operasional Sekolah untuk meringankan beban masyarakat terhadap pembiayaan pendidikan dalam rangka wajib belajar. Secara khusus program BOS bertujuan membebaskan pungutan bagi seluruh siswaSD/SLB negeri dan SMP/SMPLB/XMPT (terbuka) negeri terhadap biaya operasi sekolah kecuali pada rintisan sekolah bertaraf Internasional (RSBI). Sumbangan/pungutan tidak boleh berlebih serta membebaskan seluruh siswa miskin dari pungutan dalam bentuk apapun, baik disekolah negeri maupun swasta.

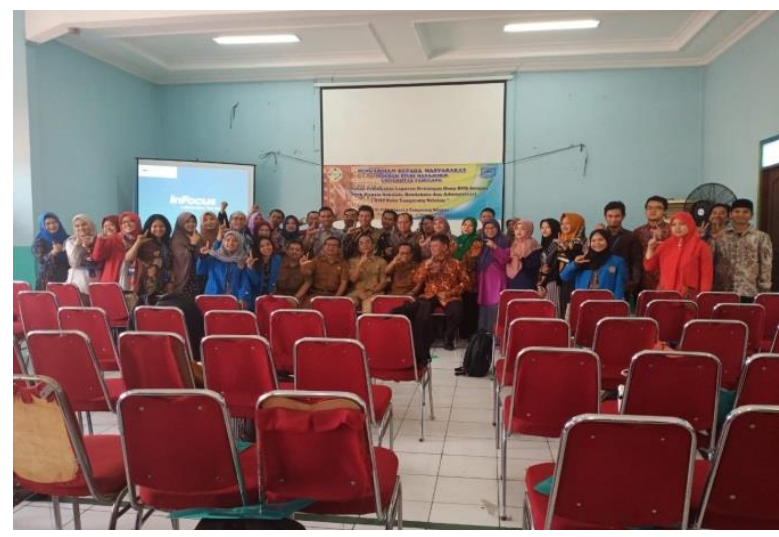

Gambar 1. Foto Bersama Kegiatan

\section{METODE PELAKSANAAN KEGIATAN}

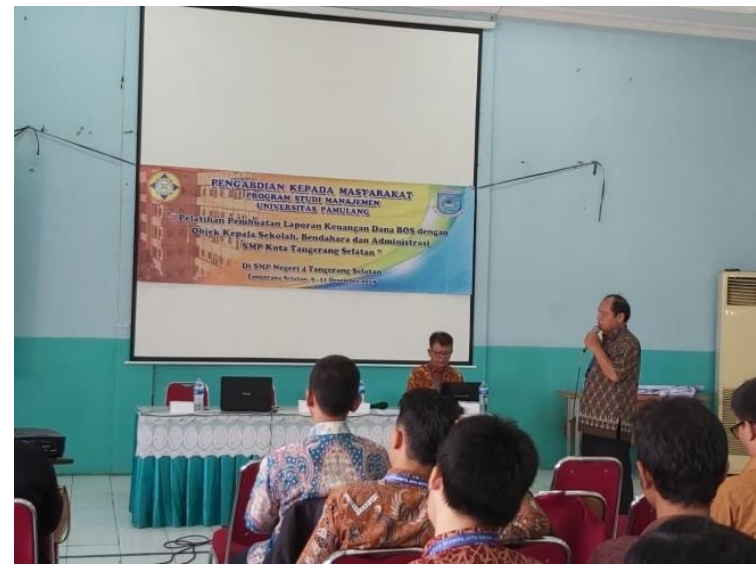

Gambar 2. Sosialisasi Dana BOS
Metode kegiatan yang digunakan yang digunakan dalam pelatihan ini yaitu berupa penyuluhan dan simposium, selanjutnya peserta akan diberikan post test untuk dikerjakan mengenai teori pembuatan laporan keuangan yang telah disampaikan kemudian dilanjutkan dengan sesi tanya jawab tentang masalah yang dihadapi. Program Pengabdian Kepada Masyarakat di SMP Negeri 4 Kota Tangerang Selatan ini dibagi mrnjadi 3 tahapan, tahap pertama

persiapan yaitu survei lapangan dan penyusunan bahan materi, tahap kedua pelaksanaan yaitu penyampaian materi dan pelatihan peserta, tahap ketiga evaluasi. Berikut adalah bagan alur dari setiap rangkaian kegiatan. 
HASIL DAN PEMBAHASAN

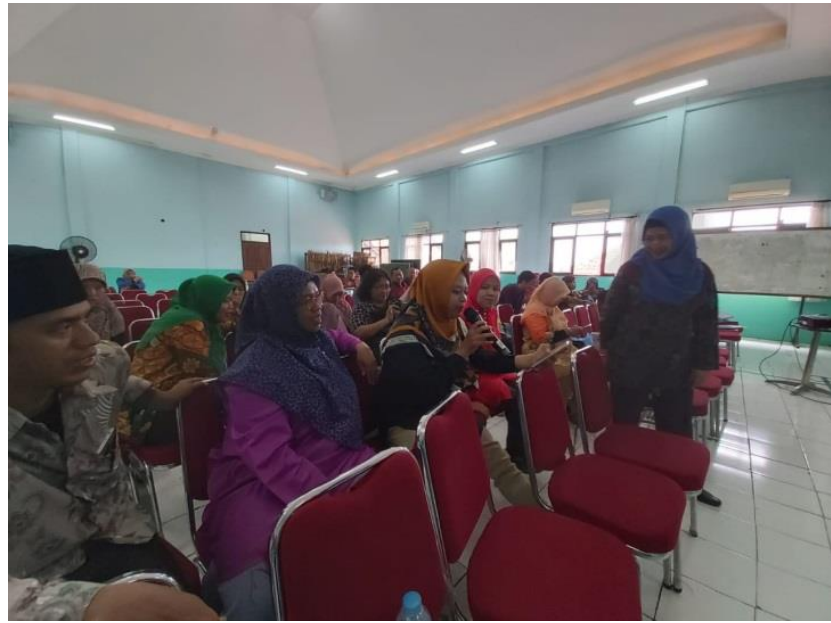

Gambar 3. Penyampaian Pengetahauian Laporan Keuangan BOS

Langkah awal metode pelaksanaan pengabdian mengenai pembuatan laporan keuangan dana BOS. Kegiatan ini dilakukan dengan tatap muka secara langsung yang disertai diskusi dan Tanya jawab mengenai materi yang disampaikan. Adapun materi yang disampaikan mengenai pembuatan laporan keuangan dana BOS yang meliputi Rencana Kegiatan ANggaran Sekolah (RKAS), Buku Kas Umum (BKU), Buku Pembantu Kas (BPK) dan Buku Pembantu Bank (BPB).

Kegiatan Pengabdian kepada Masyarakat ini dimulai dengan mendengar Curah pendapat pengalaman tentang pengelolaan dan pelaporan dana sekolah peserta, yang kemudian dilanjutkan dengan kegiatan inti yang meliputi penyampaian materi mengenai pembuatan laporan keuangan yang kemudian diakhiri dengan kegiatan akhir yaitu evaluasi program. Untuk lebih jelasnya, Tahapan kegiatan PKM ini dapat dijelaskan melalui Gambar berikut ini :

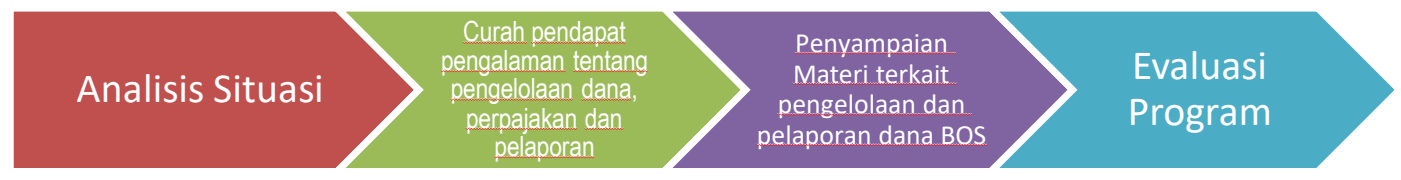

Gambar 4. Tahapan Kegiatan PKM

Luaran yang diharapkan dalam program ini adalah membantu peserta agar mampu mengelola keuangan sekolah sesuai dengan prinsip pengelolaan yang akuntabel, transparan dan efisien, serat melalui kegiatan ini peserta dapat membuat pelaporan keuangan sesuai regulasi yang berlaku, meningkatkan efektivitas dan efisiensi penggunaan dana sekolah, mendorong pemanfaatan dana sekolah lebih ekonomis, meminimalkan penggunaan anggaran sekolah dan mendorong kompetensi penanggungjawaban keuangan sekolah.

Mengacu pada identifikasi permasalahan tersebut, maka solusi yang kami berikan untuk memecahkan permasalahan yang ada adalah :

1. Menjelaskan konsep pengelolaan keuangan sekolah.

2. Menguraikan prinsip-prinsip pengelolaan keuangan.

3. Menganalisis RKAS. 
4. Menganalisis kegiatan pengelolaan dana sekolah yang sesuai dengan prinsipprinsip pengelolaan keuangan.

Mendeskripsikan pelaporan keuangan sesuai regulasi yang berlaku.

\section{KESIMPULAN DAN SARAN}

Pembuatan laporan keuangan sekolah merupakan bagian yang tidak dapat dipisahkan dalam manajemen keuangan. Secara umum, manajemen keuangan merupakan pengendalian atas fungsi keuangan. Manajemen keuangan ditingkat sekolah pada dasarnya tidak berbeda dengan manajemen keuangan secara umum, hanya saja sekolah bukanlah lembaga yang bersifat mencari profit, maka setiap penerimaan dana sekolah harus digunakan kembali untuk peningkatan kualitas dan kuantitas pelayanan pendidikan itu sendiri. Hal ini menuntut sekolah untuk melakukan pengelolaan dana pendidikan yang diperoleh secara profesional. Kepala, Bendahara dan bagian Administrasi Sekolah sebagai pengelola keuangan diharapkan memahami konsep pembuatan laporan keuangan dengan baik, sehingga mampu mengimplementasikan kegiatan pengelolaan dana sekolah dengan tepat.

Berdasarkan hasil kegiatan pengabdian kepada masyarakat pada kepala, bendahara dan bagian administrasi SMP Kota Tangerang Selatan ini diperlukan saran-saran antara lain:

Kepala, Bendahara dan bagian Administrasi harus mengetahui landasan hukum terkait dengan pengelolaan keuangan sekolah.

Kepala, Bendahara dan bagian Administrasi perlu memperhatikan prinsip-prinsip dalam pengelolaan keuangan sekolah

Kepala, Bendahara dan bagian Administrasi perlu memastikan pembukuan keuangan, dokumentasi dan pencatatan hal-hal yang terkait dengan pengelolaan keuangan dilakukan secara akurat dan tepat waktu.

\section{DAFTAR PUSTAKA}

A Sobarna, S Hambali, S Sutiswo, D Sunarsi. (2020). The influence learning used $\mathrm{ABC}$ run exercise on the sprint capabilities. Jurnal Konseling dan Pendidikan 8 (2), 67-71

A Sudarsono, D Sunarsi. (2020). Pengaruh Kualitas Pelayanan Dan Varian Produk Terhadap Keputusan Pembelian Pada Laboratorium Klinik Kimia FarmaBintaro. Value: Jurnal Manajemen dan Akuntansi 15 (1), 16-26

D Sunarsi. (2014). Pengaruh Gaya Kepemimpinan, Motivasi dan Disiplin Kerja Terhadap Kinerja Pendidik. Universitas Pamulang

D Sunarsi. (2014). Pengaruh Gaya Kepemimpinan, Motivasi dan Disiplin Kerja Terhadap Kinerja Pendidik. Universitas Pamulang

Firdaus, 2008. Dunia Pengantar Akuntansi Lengkap, Penerbit Salemba Empat ,edisi 3

Gumilar, I., Sunarsi, D. (2020). Comparison of financial performance in banking with high car and low car (Study of banks approved in the kompas 100 index for the period 2013-2017). International Journal of Psychosocial Rehabilitation. Volume 24 - Issue 7 
Maddinsyah, A., Sunarsi, D., Hermawati, R., Pranoto. (2020). Analysis of location selection effect on the user decision that influcence the success of the service business of micro, small and medium enterprise (MSME) in bandung timur region. International Journal of Advanced Science and Technology. Vol. 29 No. 06

Purwanti, P., Sarwani, S., \& Sunarsi, D. (2020). Pengaruh Inovasi Produk Dan Brand Awareness Terhadap Keputusan Pembelian Konsumen Pada Pt. Unilever Indonesia. Inovasi, 7(1), 24-31.

Sarwani, S., Suroso, S., Suwoto, S., \& Pranto Busono, P. B. (1999). Karakterisasi Kapsul Rabbit Jenis Polyethylene Naphthalene. In Prosiding Seminar Hasil Penelitian PRSG. PRSG-BATAN.

Sarwani, S., Suwoto, S., \& Sutrisno, S. (1998). Karak1ieristik Sistem Pengatur Tekanan Fa \$ Llitas Pwr/Phwr In-Pll. E Loop. In Prosiding Seminar Hasil Penelitian PRSG (pp. 14-22). PRSG-BATAN.

Sarwani, S., Syamsiah, N. O., \& Dina, F. (2018). Pemanfaatan Perangkat Lunak Akuntansi untuk Menghasilkan Laporan Keuangan pada PT. PNM ULaMM PTPM Pontianak. Moneter-Jurnal Akuntansi dan Keuangan, 5(1), 105-118.

Suharsimi Arikunto, Jabar, Abdul Cepi Safrudin, 2010, Evaluasi Program Pendidikan Jakarta, Bumi Aksara.

Sunarsi, D., \& Asmalah, L. (2018). Pelatihan Manajemen Pengembangan Diri Bagi Penerima Beasiswa RZIS UGM Dan Dompet Shalahuddin Jogjakarta. Jurnal Pengabdian Dharma Laksana, 1(1), 51-60.

Sunarsi, D., \& Erlangga, A. (2020). The Effect of Leadership Style and Work Environment on the Performance of Stationary Pump Operators in the Water Resources Office of West Jakarta City Administration. International Journal of Advances in Social and Economics, 2(3).

Sunarsi, D., Kustini, E., Lutfi, A. M., Fauzi, R. D., \& Noryani, N. (2019). Penyuluhan Wirausaha Home Industry Untuk Meningkatkan Ekonomi Keluarga Dengan Daur Ulang Barang Bekas. BAKTIMAS: Jurnal Pengabdian pada Masyarakat, 1(4), 188-193.

Sunarsi, D., Kusjono, G., \& Nuryana, I. (2019). Pelatihan Manajemen Penguasaan Kelas Dan Pembuatan Bahan Ajar Bagi Tenaga Pengajar Sukarela Taman Belajar Kreatif Mekarsari. Jurnal Pengabdian Dharma Laksana, 2(1), 41-44. Terry, George R. (2015). Dasar-dasar Manajemen. Jakarta: Bumi Aksara

Peraturan Menteri Pendidikan Nasional no. 69 tahun 2009 tentang Standar Biaya Operasional non Personalia tahun 209.

Peraturan Pemerintah (PP) no.19 tahun 2005 tentang Standar Nasional Pendidikan Peraturan Presiden no.16 tahun 2018 tentang pengadaan Barang/jasa Pemerintah. Undang-undang no.20 tahun (2003), tentang Sistem Pendidikan Nasional. 